\title{
RANK MINIMUM MATRIKS HERMITE YANG DIGAMBARKAN GRAF G
}

\author{
Mohamad Syafi'i \\ Program Studi Pendidikan Matematika STKIP Kusumanegara, Jakarta \\ moh.syafii@stkipkusumanegara.ac.id
}

\begin{abstract}
Abstrak
Rank minimum dari matriks Hermite yang digambarkan oleh graf $G$ didefinisikan dengan rank terkecil dari matriks Hermite suatu graf G. Graf yang digunakan adalah graf komplit, graf lintasan, graf sikel, graf bipartisi komplit, dan graf star. Dalam menentukan rank minimum yang digambarkan graf tersebut dengan cara membuat matriks adjacency dari graf $G$ tersebut, kemudian dikembangkan menjadi beberapa matriks Hermite, kemudian dicari rank dari beberapa matriks tersebut, sehingga diperoleh rank minimum. Dalam mencari rank matriks digunakan operasi baris elementer dan dibantu dengan program Matlab. Hasil penelitian ini diperoleh:
1. $m r\left(H_{K_{n}}\right)=1, n \in N$, dan $n \geq 2$
4. $m r\left(H_{K_{m, n}}\right)=2, m, n \in N$
2. $m r\left(H_{P_{n}}\right)=n-1, n \in N$, dan $n \geq 2$
5. $m r\left(H_{S_{n}}\right)=2, n \in N$

3. $m r\left(H_{C_{n}}\right)=n-2, n \in N$, dan $n \geq 3$
\end{abstract}

Kata Kunci: Rank Minimum, Matriks Hermite, Graf, Matriks Adjacency.

\section{PENDAHULUAN}

Matriks adjacency merupakan matriks simetri dan menjadi representasi matriks $n \times n$ yang menyatakan hubungan antar titik dalam suatu gra, bernilai 1 jika terdapat dua titik yang saling terhubung, dan bernilai 0 jika kedua titik tidak terhubung. Matriks adjacency yang didapatkan dirubah menjadi matriks Hermite, yang mana unsur - unsurnya adalah bilangan kompleks tak nol jika antar titik dalam graf tersebut terhubung langsung dan nol jika antar titik dalam graf tersebut tidak terhubung langsung, sedangkan untuk unsur diagonalnya diabaikan. Setelah dibentuk menjadi matriks Hermite, maka dapat dicari rank dari matriks Hermite tersebut, karena pemberian unsur-unsur bilangan kompleks bersifat random, maka dapat diperoleh rank minimum dari matriks Hermite yang digambarkan graf $G$. Berdasarkan pengantar tersebut peneliti ingin mengembangkan kajian ini karena pada penelitian sebelumnya telah dibahas tentang rank minimum dari matriks yang digambarkan 
dengan graf $G$ hanya dikaji dalam bentuk matriks adjacency, matriks simetri yang unsur - unsurnya modulo $Z_{n}$ dan matriks simetri real. Oleh karena itu penulis ingin mengembangkan dan meneliti tentang rank minimum pada matriks Hermite yang digambarkan pada graf $G$, sehingga diperoleh pola umum rank minimum matriks Hermite yang digambarkan oleh graf $G$.

\section{Definisi Graf}

Graf $G$ adalah pasangan $(V(G), E(G)) \quad$ dengan $\quad V(G)$ adalah himpunan tidak kosong dan berhingga dari objek - objek yang disebut sebagai titik dan $E(G)$ adalah himpunan (mungkin kososng) pasangan tak nerurutan dari titik - titik berbeda di $V(G)$ yang disebut dengan sisi. Banyaknya unsur di $V(G)$ disebut order dari $G$ dan dilambangkan dengan $p(G)$ dan banyaknya unsur di $E(G)$ disebut ukuran dari yang dilambangkan dengan $q(G)$ (Abdussakir, Azizah dan Nofandika, 2009). Suatu graf $G$ disebut terhubung (connected) jika untuk setiap titik $u$ dan $v$ di $G$ terdapat lintasan yang menghubungkan kedua titik tersebut (Chartrand dan Ortrud, 1993). Adapun graf yang digunakan pada penelitian ini adalah:

\section{Graf Komplit}

Graf $G$ adalah komplit jika setiap titik terhubung langsung ke setiap titik yang lain, graf komplit dengan $n$ titik dinyatakan dengan $K_{n}$ (Lipschutz and Lipson, 2002).

\section{Contoh:}
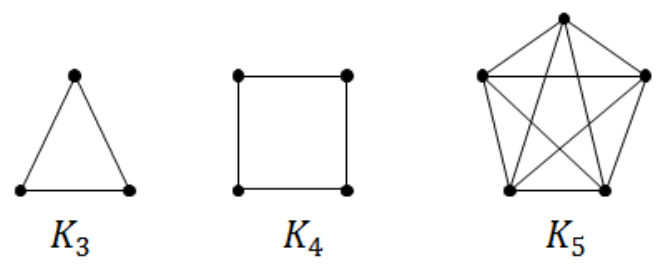

\section{Graf Lintasan}

Graf berbentuk lintasan dengan titik sebanyak $n$ dinamakan graf lintasan order $n$ dan ditulis dengan $P_{n}$ (Abdussakir, Azizah dan Nofandika, 2009).

\section{Contoh:}

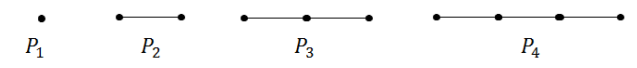

\section{Graf Sikel}

Graf berbentuk sikel dengan titik sebanyak $n, n \geq 3$, disebut graf sikel dan ditulis dengan $C_{n}$ (Abdussakir, Azizah and Nofandika, 2009).

\section{Contoh:}
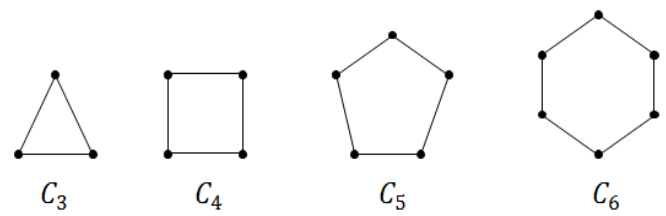

\section{Graf Bipartisi Komplit}

Graf bipartisi adalah graf yang himpunan titiknya dapat dipisahkan menjadi dua himpunan tak kosong $X$ dan $Y$ sehingga masing - masing sisi di graf tersebut menghubungkan satu titik di $X$ dan satu titik di $Y ; X$ dan $Y$ disebut himpunan partisi (Wilson and Walkins, 1990). Suatu Graf $G$ disebut bipartisi komplit jika $G$ adalah graf bipartisi dan masing - masing titik pada suatu partisi terhubung langsung dengan semua titik pada partisi yang lain. Graf bipartisi komplit dengan $m$ titik pada salah satu partisi dan $n$ titik pada partisi lain ditulis dengan $K_{m, n}$ (Abdussakir, Azizah and Nofandika, 2009).

\section{Hubungan Matriks Dengan Graf}

Misal $G$ graf dengan order $p(p \geq 1)$ dan ukuran $q$ serta himpunan semua titik $V(G)$. Matriks keterhubungan (Matriks Adjacency) dari graf $G$, dinotasikan dengan $A(G)$. Matriks Adjacency dapat ditulis sebagai berikut: 
Dengan

$$
\boldsymbol{A}=\left[a_{i j}\right]
$$

$a_{i j}=\{1$, jika titik $i$ dan $j$ saling terhubung jika titik $i$ dan j tidak saling terhubung

\section{Contoh:}
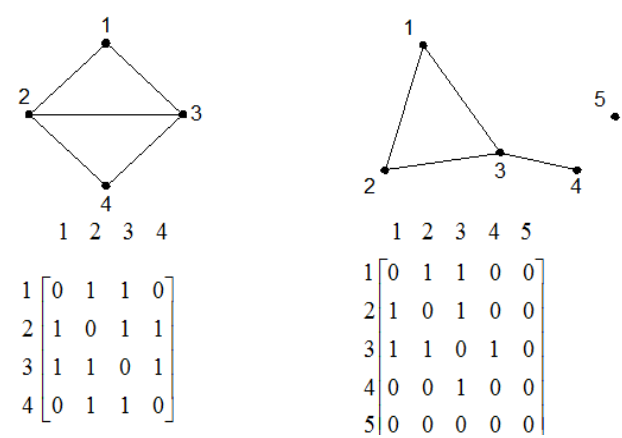

Sumber: Sumartoyo, 1983

\section{Dengan}

melihat

adanya

keterhubungan antara matriks dengan graf, maka dapat dikembangkan dengan mensubtitusi elemen dari matriks Adjacency dengan elemen bilangan kompleks yang memenuhi matriks Hermite. Adapun langkah-langkahnya sebagai berikut:

1. Diketahui graf $\mathrm{G}$

2. Membentuk matriks Adjacency dari graf tersebut

3. Membentuk matriks Hermite dari matriks Adjacency. Dengan aturan sebagai berikut:

a. Elemen diagonal diabaikan nilainya

b. Unsur nol selain di diagonal utamanya harus nol

c. Unsur tak nol pada matriks dirubah dengan unsur tidak boleh nol dengan semesta bilangan komplek dan diberikan secara random (Fallat dan Hogben, 2007).

Berdasarkan langkah-langkah diatas maka terdapat banyak kemungkinan matriks Hermite. Matriks-matriks tersebut memiliki rank masing-masing, sehingga dapat ditentukan rank minimum yang dapat didefinisikan sebagai berikut:

Rank minimum dari matriks Hermite yang digambarkan graf $G$ dapat didefinisikan: $m r\left(H_{G}\right)=\min \left\{\operatorname{rank}(A): A \in H_{G}\right\}$

Matriks bujur sangkar $A$ dengan unsur bilangan kompleks disebut Hermite, jika $A=A^{*}$ (Anton dan Rorres, 2004). Dalam memudahkan mengenali matriks Hermite, misalkan $M=\left[m_{i j}\right]$ adalah suatu matriks $m \times n$ dengan $m_{i j}=a_{i j}+i b_{i j} \quad$ untuk setiap $i$ dan $j$. Sehingga $M$ dapat ditulis dalam bentuk:

$$
M=A+i B
$$

Dengan $A=\left[a_{i j}\right]$ dan $B=\left[b_{i j}\right]$ mempunyai entri bilangan real.

Didefinisikan matriks sekawan dengan

$$
\bar{M}=A-i B
$$

Jadi $\bar{M}$ adalah matriks yang terbentuk dengan mengambil komples sekawan dari setiap entri $M$. Tranpose dari $\bar{M}$ dilambangkan dengan $M^{H}$, jadi suatu matriks $M$ disebut Hermite jika $M=M^{H}$

\section{Contoh:}

$$
A=\left[\begin{array}{ccc}
1 & i & 1+i \\
-i & -5 & 2-i \\
1-i & 2+i & 3
\end{array}\right]
$$

Maka

$$
\bar{A}=\left[\begin{array}{ccc}
1 & -i & 1-i \\
i & -5 & 2+i \\
1+i & 2-i & 3
\end{array}\right]
$$

Sehingga

$$
A^{*}=\bar{A}^{T}=\left[\begin{array}{ccc}
1 & i & 1+i \\
-i & -5 & 2-i \\
1-i & 2+i & 3
\end{array}\right]=A
$$

Jadi $A$ adalah matriks Hermite.

Rank dari suatu matriks $A$ adalah dimensi dari ruang baris $A$ (Leon, 2001). Menentukan rank dari suatu matriks, dengan mereduksi matriks yang bersangkutan menjadi bentuk eselon baris. Baris-baris tak nol dari matriks eselon baris akan membentuk basis untuk ruang basisnya. 
Adapun teorema-teorema yang

mendukung penelitian ini adalah sebagai berikut (Fallat dan Hogben, 2007):

\section{Teorema 1.}

Diberikan suatu graf $G$ dengan $n$ titik $v \in V(G)$

$$
m r(G)-2 \leq m r(G-v) \leq m r(G) .
$$

\section{Teorema 2.}

Untuk setiap field $F$ dan graf $G$ dengan order $n$, maka $m r(G) \leq|G|-1$

\section{Teorema 3.}

Untuk graf $G$ dengan order $n$ maka $m r(G) \geq \operatorname{diam}(G)$.

$\operatorname{diam}(G)$ atau diameter suatu graf $G$ merupakan jarak terbesar antara dua titik yang terdapat pada graf $G$.

\section{METODE PENELITIAN}

Metode yang dilakukan dalam penelitian ini adalah melalui studi kepustakaan dengan mempelajari buku, makalah, dan penelitian sebelumnya yang berkaitan rank minimum pada matriks yang digambarkan Graf $\mathrm{G}$ untuk digunakan sebagai dasar teori.

\section{HASIL DAN PEMBAHASAN}

Pada awal pembahasan ini diterapkan pada Graf komplit $\left(K_{n}\right)$ dengan n titik, dimana $n \in N, n \geq 2$, graf komplit merupakan graf sederhana yang setiap titiknya terhubung ke titik yang lainnya. Di bawah ini adalah graf $K_{6}$ yang merupakan contoh dari graf komplit dengan 6 titik.

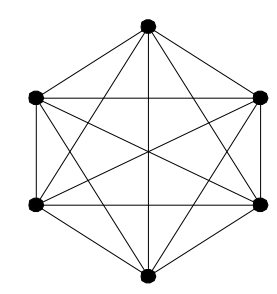

Gambar 1. Graf $K_{6}$
Matriks adjacency graf komplit $\left(K_{n}\right)$ tersebut adalah sebagai berikut:

$$
A_{K_{n}}:\left[\begin{array}{ccccc}
0 & 1 & 1 & \ldots & 1 \\
1 & 0 & 1 & \ldots & 1 \\
1 & 1 & 0 & \ldots & 1 \\
\vdots & \vdots & \vdots & \ddots & \vdots \\
1 & 1 & 1 & \ldots & 0
\end{array}\right]
$$

Berdasarkan matriks adjacency tersebut dibentuk menjadi matriks Hermite dengan cara:

1. Unsur diagonal diabaikan nilainya

2. Unsur nol selain di diagonal utama tetap nol

3. Unsur tak nol pada matriks diganti dengan konstanta tak nol secara random

Dikarenakan tujuan penelitian ini adalah mencari rank minimum dari matriks Hermite dan terdapat beberapa kemungkinan bentuk matriks Hermite yang dapat digambarkan graf $K_{n}$, oleh karena itu di cari bentuk pola matriks Hermite yang mempunyai nilai rank paling minimum dengan berpedoman pada Teorema 3.

\section{Teorema 4.}

Jika $K_{n}$ graf komplit dengan $n$ titik dimana $n \in N$ dan $n \geq 2$, maka $m r\left(H_{K_{n}}\right)=1$.

\section{Bukti:}

Diketahui : Graf komplit $\left(K_{n}\right)$ dengan $n$ titik dimana $n \in N$ dan $n \geq 2$.

Maka matrik adjacency dari graf $K_{n}$ adalah:

$$
A_{K_{n}}:\left[\begin{array}{ccccc}
0 & 1 & 1 & \ldots & 1 \\
1 & 0 & 1 & \ldots & 1 \\
1 & 1 & 0 & \ldots & 1 \\
\vdots & \vdots & \vdots & \ddots & \vdots \\
1 & 1 & 1 & \ldots & 0
\end{array}\right]
$$

Akan dibuktikan bahwa $m r\left(H_{K_{n}}\right)=1$ Berdasarkan Teorema 3 diperoleh $m r\left(H_{K_{n}}\right) \geq \operatorname{diam}\left(H_{K_{n}}\right)=1 . \quad$ Sehingga $m r\left(H_{K_{n}}\right) \geq 1$. Cukup ditunjukkan bahwa $m r\left(H_{K_{n}}\right) \leq 1$. Untuk memperoleh matriks Hermite dengan $m r\left(H_{K_{n}}\right)=1$, maka diambil matriks secara random (acak). Adapun untuk mempermudah mendapatkan pola matriks Hermite dengan minimum rank 1 , maka penulis dibantu dengan menggunakan program Matlab, 
FIBONACCI : Jurnal Pendidikan Matematika dan Matematika. Vol. 4 (2), pp:97-104.

sehingga didapatkan pola matriks Hermite sebagai berikut

$$
H_{K_{n}}:\left[\begin{array}{ccccc}
a & -a i & -a i & \ldots & -a i \\
a i & a & a & \ldots & a \\
a i & a & a & \cdots & a \\
\vdots & \vdots & \vdots & \ddots & \vdots \\
a i & a & a & \cdots & a
\end{array}\right]
$$

Dimana rank dari matriks Hermite tersebut adalah 1.

Ambil matriks Hermite:

$$
H_{K_{n}}:\left[\begin{array}{ccccc}
a & -a i & -a i & \ldots & -a i \\
a i & a & a & \ldots . & a \\
a i & a & a & \ddots & a \\
\vdots & \vdots & \vdots & . & \vdots \\
a i & a & a & \cdots & a
\end{array}\right]
$$

dengan $a \in \mathbb{R}, a \neq 0$, dan $i=\sqrt{-1}$

dengan menggunakan eliminasi Gauss-Jordan, diperoleh rank dari matriks Hermite tersebut adalah 1. Jadi $\operatorname{mr}\left(H_{K_{n}}\right) \leq 1$, Karena $m r\left(H_{K_{n}}\right) \geq 1$ dan $\operatorname{mr}\left(H_{K_{n}}\right) \leq 1$ maka $m r\left(H_{K_{n}}\right)=1$. Sehingga Teorema 4 terbukti.

Bentuk matriks adjacency dari graf $K_{6}$ di atas adalah:

$$
A_{K_{6}}:\left[\begin{array}{llllll}
0 & 1 & 1 & 1 & 1 & 1 \\
1 & 0 & 1 & 1 & 1 & 1 \\
1 & 1 & 0 & 1 & 1 & 1 \\
1 & 1 & 1 & 0 & 1 & 1 \\
1 & 1 & 1 & 1 & 0 & 1 \\
1 & 1 & 1 & 1 & 1 & 0
\end{array}\right]
$$

Salah satu kemungkinan Matriks Hermite dari matriks adjacency yang digambarkan graf $K_{6}$ Adalah:

$$
H_{K_{6}}:\left[\begin{array}{cccccc}
7 & -7 i & -7 i & -7 i & -7 i & -7 i \\
-7 i & 7 & 7 & 7 & 7 & 7 \\
-7 i & 7 & 7 & 7 & 7 & 7 \\
-7 i & 7 & 7 & 7 & 7 & 7 \\
-7 i & 7 & 7 & 7 & 7 & 7 \\
-7 i & 7 & 7 & 7 & 7 & 7
\end{array}\right]
$$

Menggunakan program Matlab diperoleh $R\left(H_{K_{6}}\right)=1$.

Berdasarkan langkah - langkah dalam menentukan $\operatorname{mr}\left(H_{K_{n}}\right)$, dapat diterapkan pula dengan bentuk graf lain. Pada penelitian ini selain menentukan $\operatorname{mr}\left(H_{K_{n}}\right)$ juga mencari $m r\left(H_{P_{n}}\right), \quad m r\left(H_{C_{n}}\right)$, $m r\left(H_{K_{m, n}}\right), m r\left(H_{S_{n}}\right)$.

\section{Teorema 5.}

Jika $P_{n}$ graf lintasan dengan $n$ titik dimana $n \in N$ dan $n \geq 2$, maka $m r\left(H_{P_{n}}\right)=n-1$ (Chenette dan Droms, 2007).

\section{Bukti:}

Diketahui : Graf lintasan $\left(P_{n}\right)$ dengan $n$ titik dimana $n \in N$ dan $n \geq 2$.

Maka matrik adjacency dari graf $P_{n}$ adalah:

$$
A_{P_{n}}:\left[\begin{array}{ccccc}
0 & 1 & 0 & \ldots & 0 \\
1 & 0 & 1 & \ldots & 0 \\
0 & 1 & 0 & \ldots & 0 \\
\vdots & \vdots & \vdots & \ddots & \vdots \\
0 & 0 & 0 & \ldots & 0
\end{array}\right]
$$

Akan dibuktikan bahwa $m r\left(H_{P_{n}}\right)=n-1$ Berdasarkan Teorema 3 . diperoleh $m r\left(H_{P_{n}}\right) \geq \operatorname{diam}\left(H_{P_{n}}\right)=n-1$. Sehingga $m r\left(H_{P_{n}}\right) \geq n-1$. Cukup ditunjukkan bahwa $m r\left(H_{P_{n}}\right) \leq n-1$

Ambil matriks Hermite:

$$
H_{P_{n}}:\left[\begin{array}{ccccc}
a i & a i & 0 & \ldots & 0 \\
-a i & 0 & a i & \ldots & 0 \\
0 & -a i & 0 & \ddots & 0 \\
\vdots & \vdots & \vdots & \ddots & \vdots \\
0 & a & a & \cdots & -a i
\end{array}\right]
$$

dengan $a \in \mathbb{R}, a \neq 0$, dan $i=\sqrt{-1}$.

dengan menggunakan eliminasi Gauss-Jordan, diperoleh rank dari matriks Hermite tersebut adalah $n-1$. Jadi $m r\left(H_{P_{n}}\right) \leq n-1$. Karena $m r\left(H_{P_{n}}\right) \geq n-1$ dan $\operatorname{mr}\left(H_{P_{n}}\right) \leq n-1$ maka $\operatorname{mr}\left(H_{P_{n}}\right)=n-1$. Sehingga Teorema 5 terbukti.

\section{Teorema 6.}

Jika $C_{n}$ graf sikel dengan $n$ titik dimana $n \in N$ dan $n \geq 3$, maka $m r\left(H_{C_{n}}\right)=n-2$.

\section{Bukti:}


Diketahui : Graf sikel $\left(C_{n}\right)$ dengan $n$ titik dimana $n \in N$ dan $n \geq 3$. Maka matrik adjacency dari graf $C_{n}$ adalah:

$$
A_{C_{n}}:\left[\begin{array}{ccccc}
0 & 1 & 0 & \ldots & 1 \\
1 & 0 & 1 & \ldots & 0 \\
0 & 1 & 0 & \ldots & 0 \\
\vdots & \vdots & \vdots & \ddots & \vdots \\
1 & 0 & 0 & \ldots & 0
\end{array}\right]
$$

Akan dibuktikan bahwa $m r\left(H_{C_{n}}\right)=n-2$, Graf sikel $\left(C_{n}\right)$ bukan merupakan graf lintasan $\left(P_{n}\right)$. Akan tetapi graf sikel $\left(C_{n}\right)$ memuat subgraf lintasan terdukung dengan lintasan $n-1$ titik $\left(P_{n-1}\right)$, berdasarkan Teorema 1 . diperoleh:

$$
\begin{aligned}
& \operatorname{mr}\left(H_{C_{n}}\right) \geq \operatorname{mr}\left(H_{P_{n-1}}\right) \\
& \operatorname{mr}\left(H_{C_{n}}\right) \geq(n-1)-1 \\
& \operatorname{mr}\left(H_{C_{n}}\right) \geq n-2
\end{aligned}
$$

Sehingga diperoleh $m r\left(H_{C_{n}}\right) \geq n-2$. Cukup ditunjukkan bahwa $m r\left(H_{C_{n}}\right) \leq n-2$ Ambil matriks Hermite:

Dengan $n=3$, karen $C_{3}=K_{3}$ maka diperoleh $m r\left(H_{C_{3}}\right)=1$

Untuk $n \geq 4$, ambil matriks Adjacency dari graf sikel atau $A_{C_{n}}$ maka:

- $n \equiv 0 \bmod 4$ maka pilih matriks $A_{C_{n}}+\operatorname{diag}(0,-1,0,1,0,-1,0,1, \ldots, 0,-1,0,1)$.

- $n \equiv 1 \bmod 4$, dan $n \geq 5$ maka pilih matriks $A_{C_{n}}+\operatorname{diag}(-1,-1,-1,0,0,0, \ldots, 0,0,0)$.

- $n \equiv 2 \bmod 4$, dan $n \geq 6$ maka pilih matriks $A_{C_{n}}+\operatorname{diag}(1,1,1,1,1,1,0,0, \ldots, 0,0,0)$.

- $n \equiv 3 \bmod 4$, dan $n \geq 7$ maka pilih matriks

$A_{C_{n}}+\operatorname{diag}(1,1,1,0,0,0, \ldots, 0,0,0)$.

Dengan menggunakan program Matlab, maka diperoleh Rank dari matriks - matriks tersebut adalah $n-2$. Jadi $m r\left(H_{C_{n}}\right) \leq n-2$. Karena $m r\left(H_{C_{n}}\right) \geq n-2$ dan $m r\left(H_{C_{n}}\right) \leq n-2$ maka $m r\left(H_{C_{n}}\right)=n-2$. Sehingga teorema 5 terbukti.

\section{Teorema 7.}

Jika $K_{m, n}$ graf bipartisis komplit dengan $n+m$ titik dimana $m, n \in N$, maka $m r\left(H_{K_{m, n}}\right)=2$.

\section{Bukti:}

Diketahui: Graf bipartisi komplit $\left(K_{m, n}\right)$ dengan $m+n$ titik dimana $m, n \in N$. Maka matrik adjacency dari graf $K_{m, n}$ adalah:

$\left.\begin{array}{ccccccccccc}A_{K_{m, n}}: & 1 & 1 & 2 & \ldots & \mathrm{m} & \mathrm{m}+1 & \mathrm{~m}+2 & \ldots & \mathrm{m}+\mathrm{n} \\ & \vdots & 0 & 0 & \ldots & 0 & 1 & 1 & \ldots & 1 \\ & \mathrm{~m} & 0 & \ldots & 0 & 1 & 1 & \ldots & 1 \\ & \mathrm{~m} & \vdots & \ddots & \vdots & \vdots & \vdots & \ddots & \vdots \\ & \mathrm{m}+1 & 0 & \ldots & 0 & 1 & 1 & \ldots & 1 \\ & \mathrm{~m}+2 & 1 & \ldots & 1 & 0 & 0 & \ldots & 0 \\ & \vdots & \vdots & 1 & \ldots & 1 & 0 & 0 & \ldots & 0 \\ \mathrm{~m}+\mathrm{n} & \vdots & \ddots & \vdots & \vdots & \vdots & \ddots & \vdots \\ 1 & 1 & \ldots & 1 & 0 & 0 & \ldots & 0\end{array}\right]$

Akan dibuktikan bahwa $m r\left(H_{K_{m, n}}\right)=2$ Berdasarkan Teorema 3. diperoleh $m r\left(H_{K_{m, n}}\right) \geq \operatorname{diam}\left(H_{K_{m, n}}\right)=2$. Sehingga $m r\left(H_{K_{m, n}}\right) \geq 2$. Cukup ditunjukkan bahwa $m r\left(H_{K_{m, n}}\right) \leq 2$. Ambil matriks Hermite:

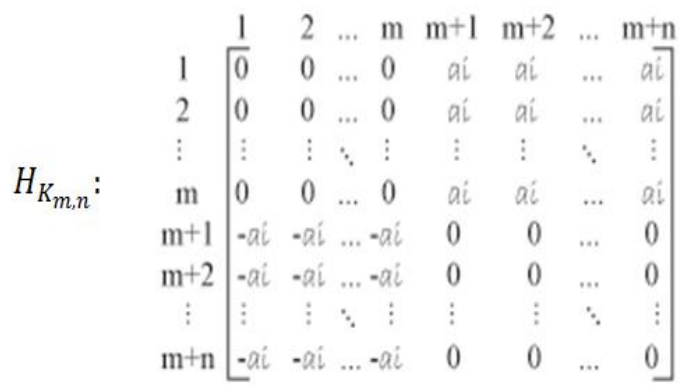

dengan $a \in \mathbb{R}, a \neq 0$, dan $i=\sqrt{-1}$. Dengan menggunakan eliminasi Gauss-Jordan, diperoleh rank dari matriks Hermite tersebut adalah 2. Jadi $m r\left(H_{K_{m, n}}\right) \leq 2$. Karena $m r\left(H_{K_{m, n}}\right) \geq 2$ dan $\operatorname{mr}\left(H_{K_{m, n}}\right) \leq 2$ maka $m r\left(H_{K_{m, n}}\right)=2$. Sehingga Teorema 7 . Terbukti.

Akibat Teorema 7. dapat disimpulkan bahwa $m r\left(H_{S_{n}}\right)=2$, dikarenakan graf bintang $\left(S_{n}\right)$ sama dengan graf bipartisi komplit dengan bentuk $K_{1, n}$ 


\section{Teorema 8.}

Jika $S_{n}$ merupakan graf bintang dengan $n \in N$, maka $\operatorname{mr}\left(H_{S_{n}}\right)=2$.

\section{SIMPULAN}

Berdasarkan pembahasan tentang rank minimum dari matriks Hermite yang digambarkan oleh Graf $G$, diperoleh kesimpulan:

1. Rank minimum matriks Hermite yang digambarkan graf $K_{n}$ (graf komplit dengan $n$ titik, $n \geq 2)$ adalah 1 atau $\operatorname{mr}\left(H_{K_{n}}\right)=$ 1.

2. Rank minimum matriks Hermite yang digambarkan graf $P_{n}$ (graf lintasan dengan $n$ titik, $n \geq 2$ ) adalah $n-1$ atau $m r\left(H_{P_{n}}\right)=n-1$.

3. Rank minimum matriks Hermite yang digambarkan graf $C_{n}$ (graf sikel dengan $n$ titik, $n \geq 3$ ) adalah $n-2$ atau $m r\left(H_{C_{n}}\right)=n-2$.

4. Rank minimum matriks Hermite yang digambarkan graf $K_{m, n}$ (graf bipartisi dengan $m+n$ titik, $m, n \in N$ ) adalah 2 atau $m r\left(H_{K_{m, n}}\right)=2$.

5. Rank minimum matriks Hermite yang digambarkan graf $S_{n}$ (graf bintang dengan $n+1$ titik, $n \in N)$ adalah 2 atau $m r\left(H_{S_{n}}\right)=2$.

\section{DAFTAR PUSTAKA}

Abdussakir, Azizah, N. N. dan Nofandika, F. F. 2009. Teori Graf. Malang: UIN-Malang Press.

Anton, H. dan Rorres, C. 2004. Aljabar Linier Elementer. Jakarta: Erlangga.

Chartrand, G. dan Ortrud, O. 1993. Applied and Algorithmic Graph Theory. Canada: McGraw-Hill Inc.

Chenette, Nathan L. dan Droms, S. V. 2007. "Minimum Rank of a Graph Over an Arbitrary Field". Electronic Journal of Linear Algebra. Vol. 16, pp. 183-186.

Fallat, S. dan Hogben, L. 2007. "The Minimum Rank of Symmetric Matrices Described by a Graph: A Survey”. Linear Algebra and Its Applications. Vol. 462, pp. 558-582.

Leon, S. J. 2001. Aljabar Linear dan Aplikasinya. Jakarta: Erlangga.

Lipschutz, S. dan Lipson, M. L. 2002. Matematika Diskrit. Jakarta: Penerbit Salemba Teknika.

Sumartoyo, N. N. 1983. Aljabar Linear. Jakarta: Erlangga.

Wilson, R. J. dan Walkins, J. J.1990. Graphs an Intoductory Approach: A First Course in Discrete Mathematic. New York: John Wiley \& Sons Inc 
FIBONACCI : Jurnal Pendidikan Matematika dan Matematika

Volume 4 No.2 Bulan Desember Tahun 2018 